\title{
Tunisia Post Revolution: Confronting Social problems, Economic Challenges and Regional Disparity
}

\author{
Sawssen Nafti ${ }^{1}$, Fatma Mrad $^{1} \&$ Ahlem Boubker ${ }^{2}$ \\ 1 Faculty of Economics and Management of Sousse Laboratory, University of Sousse, Sousse, Tunisia \\ ${ }^{2}$ Higher Institut of Management of Gabès, Tunisia \\ Correspondence: Sawsen Naftti, TunisiaFaculty of Economics and Management of Sousse Laboratory, University \\ of Sousse, Street of Khalifa El Karoui Sahloul - BP $n^{\circ} 526$ - 4002, Sousse, Tunisia. E-mail: \\ sawssen_nafti@yahoo.fr
}

Received: June 25, 2021

Accepted: August 10, 2021

Online Published: August 15, 2021

doi:10.5539/ijef.v13n9p127

URL: https://doi.org/10.5539/ijef.v13n9p127

\begin{abstract}
The present paper attempts to know if inclusive growth in Tunisia after revolution is a solution to poverty, social inequality and regional disparity or not. Firstly, by analyzing the concept of poverty and equality in Tunisia. Then via the determination of causes of unemployment and regional disparity. Finally through the study of the nexus relationship between economic growth, poverty reducing.According to our analysis, some issues necessed short-term solutions, others require a more long-term or structural change.In the long term, inclusive growth strategy could be adopted, providing for investment especially in infrastructure and public services and reducing regional disparity.
\end{abstract}

Keywords: poverty, inequality, regional disparity, economic development

JEL classifications: D63, I30, Q18.

\section{Introduction}

Tunisian revolution has tripped due to the unemployment problem, poverty, regional disparity and inequality. From the point of view of social welfare, it is important to understand the origins of this revolution, to prevent their economic and social costs. The Tunisian GDP grew about 5\% per year, over the last twenty years and the country has been cited as one of the best performing economies, especially within the region. Tunisian authorities also highlighted the excellent results in terms of human capital. In fact, the percentage of poverty has fallen dramatically, from $15.5 \%$ in 1990 to about $5 \%$ in 2005 . However, improved access to education and health is not enough to ensure the development. Namely, the Tunisian labor market has not been able to create enough jobs for new entrants which have exacerbated poverty again, and also the hunger as a result of poverty and unequal development between regions. Also, the fruits of sustainable economic growth have not been evenly distributed across the regions. However, some regions have benefited from the economic growth and the reduction of poverty, while other regions have seen their situation deteriorate. As a result, unemployment and inequality indices have therefore worsened.

Access to food is the right of all humans by multiple international legal regulations absolute right. This law is applied inter alia, the Universal Declaration of Human Rights in its Article 25, the International Covenant on Economic, Social and Cultural Rights of 1966 through Articles 2 and 11 as well as the Convention on food aid (1986) in its first article, but today many people in the world and in Tunisia don't able to eat in their hunger. In fact, the Tunisian revolution has tripped due to the problem of unemployment, poverty, regional disparity and inequality that leads most people to the inner regions of the catastrophic situation of food shortage, hunger ..., The Tunisian revolution marked the beginning of the Arab Spring and the country engaged in a process of democratic transition. Although the issues discussed especially hunger, poverty and inequality remain key challenges for future Tunisian government must tackle.If for now the priority is to manage the political transition and ensure macroeconomic and social stability, these substantive issues can't be ignored. Social inequality and regional disparity have also contributed to the discontent behind the revolution. The increase in per capita income had hidden social inequality and persistent regional disparity, thereby distorting the reality of the situation in the inland areas where the main subject of the revolution. The concentration of investment and public services, and economic activities in coastal areas has increased poverty (in terms of number of poor as inequality) and unemployment in other regions. 
The present work reports the impact of inclusive growth in Tunisia after revolution to solve the problems of poverty, social inequality and regional disparity, in the period range between 2011-2020. This study is organized as follow: Firstly, we show the definition of povrety. Secondly, we give the implications of povrety and inequality in Tunisia, Thirdly, we proposed the different policies to reduce poverty and inequality un Tunisia.

\section{Definition of Concepts}

\subsection{Poverty}

According to Lipton and Ravallion (1995), poverty refers to the situation of a person who does'nt reach a certain level of consumption of goods and services considered to represent a reasonable minimum threshold (the poverty line), both in absolute terms (absolute poverty) or according to the standards defined by a given society (relative poverty or relative deprivation).

\subsubsection{The Absolute Poverty}

This is the minimum standard of living (income), needed to escape poverty. In other words, the absolute poverty line is the level of income below (above) in which a person falls (escapes) in absolute poverty. It is defined in real terms and does not vary depending on the overall standard of living of the population.

\subsubsection{The Relative Poverty}

line Unlike the threshold of absolute poverty, relative poverty line runs parallel to the overall standard of living of the population. It is usually expressed as a fraction of median income.

\subsection{The Poverty Indicator}

An indicator of poverty is obtained by applying the aggregation procedure for the distribution of differences between the poverty line and individual incomes. There are many statistics on poverty, the most popular is the poverty rate (also called proportion of poor or poverty incidence). It corresponds to the proportion of people whose income level is below the poverty line.

- The use of absolute poverty to define indicators of absolute poverty, while the use of a relative poverty is reflected in indicators of relative poverty.

- Indicators of relative poverty are also considered indicators of social exclusion.

- The inter-group inequality.

The term typically refers to inequality of income differences between individuals, but it can also refer to inequality between groups defined by gender, race, region, etc.. So the term inter-group inequality is the level of inequality calculated for the distribution of the regional median income. For example, if we consider the following distribution $(100,300,500,700)$, with an overall median of 400 . Suppose that the distribution is divided into two groups $(100,300)$ for the region A whose median income is 200 and $(500,700)$ for the region B whose median income is 600 . Intergroup inequality is calculated for the distribution $(200,200,600,600)$, which is actually a counterfactual distribution where each individual is assigned the median income of the region.

\subsection{The Intra-Group Inequality}

The within-group inequality is a weighted sum of inequality within each group (or region, in the case of this study). It can be calculated on the basis of a free inequality intergroup counterfactual. For this counterfactual, the income of each individual is adjusted by the ratio of the overall median reported the median of the region, so that the median income in each region is equal to the median of the overall distribution. If we take the above example of a distribution $(100,300,500,700)$, the income of each individual region A (B) is adjusted by the ratio of 400 to 200 (600). The intra-group inequality is then calculated for the distribution (200, 600, 333.33, 466.67). It should be noted that this counterfactual is free of inequalities between groups, with a median income of each region is 400 .

In short, if global inequality is calculated for a distribution $(100,300,500,700)$ with a distribution of $(100,300)$ for region $\mathrm{A}$ and $(500,700)$ for the region $\mathrm{B}$, the overall inequality for $(100,300,500,700)$ will be the sum of the inter-group inequality for $(200,200,600,600)$ and within-group inequality for $(200,600,333.33,466,67)$.

\section{Poverty and Inequality in Tunisia}

\subsection{Poverty}

Tunisia was considered to have succeeded the social development that has accompanied economic development. Sustained economic growth and proactive social development policy having accompanied helped improve social indicators. Tunisia should meet most of the Millennium Development Goals (MDGs). With a Human Development Index (HDI) of 0.698 in 2011, Tunisia is ranked 94th out of 187 countries in the category of countries 
with "high human development", thus positioning above the average of the continent and the Arab countries. In this sense, in terms of human development index adjusted for inequality, Tunisia loses seven rows, with a score of 0.523 . From that improving overall social indicators implied a rise in inequality in income distribution.

\subsubsection{Poverty Figures}

The official poverty rate provided by the INS, which was down $6.7 \%$ in 1990 to $3.8 \%$ in 2005 , does'nt really reflect the incidence of poverty in Tunisia. According to the INS, the official poverty rate is calculated from the reference threshold of extreme poverty which is 365 dinars per year. However, using a higher threshold that takes into account the basic expenses of additional households, the rate is $11.5 \%$ and reached $29.4 \%$ in the Central West region.

According to estimates made by the Project of the World Bank global poverty, the poverty incidence in 2005 was 7\%. However, in May 2011, the Ministry of Social Affairs of Tunisia has issued its own national poverty rate, estimated at $24.7 \%$, which is calculated on the basis of information gathered from needy families and beneficiaries of social programs. If this publication has generated a public debate on the transparency of data especially the INS is that its methodological foundation was not strong enough and it raises doubts about the criteria adopted for the identification of needy families.

Whatever the level of poverty, Tunisia has managed to reduce poverty, but inequality remains a major challenge. Economic growth has reduced poverty; however there is an increase in the Gini coefficient, especially during the 2000s, from 39.3 in 2000 to 42.1 in 2005. In 2000, on the basis of consumption expenditure per household, it is estimated that nearly $10 \%$ of the population lived on less than $\$ 2$ a day, and $18 \%$ with less than 3 dollars. In addition, significant inequalities persisted half the population in the lower fringe absorbs about $25 \%$ of total energy consumption by $20 \%$ against the population in the lower fringe absorbs only $8 \%$ of the total consumption.

\subsubsection{Poverty by Regions}

The inequality is clearly observed between the metropolitan areas of Tunis occupies the lowest poverty rate; however, the most poverty-stricken areas are located within the country, especially in the Midwest, South West and also the Southeast.

The trend is the same when we refer to the poverty data of the NSI. In this sense, the poverty rate (number of people living with three dollars) was reduced by $23 \%$ in 1990 to $18 \%$ in 2000 , the general trend has been observed in most regions, except the Southeast. The region has benefited the most from the decline in poverty is the Northwest, with a rate from $38 \%$ in 1990 to $20 \%$ in 2000. The trend is the same for the intensity of poverty, regions where the average poverty gap is highest are also those with the most poor Central West, South West and Southeast.

In all regions, the average poverty gap undergoes a decrease from $6.6 \%$ to $4.7 \%$ at the national level with the exception of the South-East by the North against West has achieved the highest reduction in poverty, with a rate from $12 \%$ in 1990 to $4 \%$ in 2000 . Note that the North-West, which was the poorest in 1990, became the third richest region in 2000 ,

In another sense, further analysis shows that in some governorates, poverty has increased dramatically, despite at national level, as regional, she continued to decline. One can cite the case of Kasserine where rates of absolute and relative poverty both increased from $19.3 \%$ to $30.7 \%$ and $30.3 \%$ to $49.3 \%$ respectively between 1990 and 2000 . During the same period, the relative poverty rate has also increased in Sidi Bouzid, from $39.8 \%$ to $45.7 \%$.

The same analysis indicated that growth is pro-poor in Tunisia, which explains the increase in inequality and social exclusion. Resentment born and worsens the social exclusion explains why so clear social unrest that preceded the revolution were triggered in these governorates.

\subsection{Regional Disparity}

\subsubsection{Regional Disparity in Public Services}

Regional disparity are exacerbated by the concentration of public services, investment and economic activities in the coastal region, as a result, the inland areas are underserved and marginalized in terms of public services. For example, the governorate of Jendouba the least served in terms of primary health care, with 1.4 general practitioner in public health for 10000 and less than 1.7 Sidi Bouzid, Gafsa and Medenine, against a national average of 2.7. By cons in the city of Tunis, the rate is 4.3 .

Also regional disparity affects the number of hospital beds, as the illiteracy rate is $30 \%$ in rural areas against $15 \%$ in urban areas and 23\% nationally. In addition, the excessive concentration of Directors attended the neglect of public services, including basic services in the interior regions. In addition, the high concentration of economic 
activities in the North- East and Central-East has fostered regional disparities, the coastal region with $75 \%$ of nonagricultural jobs. The governorate of Tunis has absorbed $23 \%$ of all job offers against only $4 \%$ in the Southeast in 2010, although the region accounts for $9 \%$ of the total population. Almost half, as the number of companies that power consumption (high and medium intensity), is concentrated in the North-East, for against the western regions represent less than $3 \%$ of companies with less than $5 \%$ of electricity consumption. In short, the significant reduction of poverty in the North West is a consequence of the significant public and private investment to the region benefited during the1990s.

\subsubsection{Regional Disparity in Unemployment}

Regional disparity has led to higher unemployment in the interior regions, affecting the poorest. For example, the unemployment rate was higher than $21 \%$ Kasserine, Gafsa and $28 \%$ to $24 \%$ in Tataouine while the national average was 13\% in 2010. In the same vein, 47\% in Gafsa, Sidi Bouzid 41\%, 43\% and 40\% Kébili Jendouba have unemployment rates higher graduates, against a national average of $23 \%$.

In general, in Tunisia, the higher of the education level, the higher the unemployment rate is high. This explains why in recent decades, the poverty rate has decreased more in non- educated households (32\% 25\%) than in educated households (about 15\%). In this sense, unemployment is higher among young people, with almost $30 \%$ unemployment among the age group of 15-24 years, and 24\% in the age group of 24-29 years, against less than 4\% in the age group of 40-49 year olds.

In fact, the development of Tunisia is based on intensive production work force in turn increase the demand for unskilled labor. In addition, unemployment is higher among women (19\% in 2010) than men (11\%), and affects twice as many women graduates $(33 \%)$ than male graduates $(16 \%)$. These figures are far from the reality of unemployment in Tunisia because they are not listed on the official labor market. A quote that $63 \%$ of young women with no qualifications are declared inactive against only $9 \%$ of men in the same situation. As against only $18 \%$ of unskilled women are estimated to be unemployed as against $20 \%$ for unskilled men. In addition, although there is $67 \%$ of women who go for higher education (2008-2009), only $25 \%$ are active in the labor market. Even among women age 20 to 29 years, less than $35 \%$ are present. In short, this paradoxical trend indicates the existence of strong discrimination in the labor market against women. It is also important to note that despite their increasing share among graduates, $16 \%$ of women in the $25-29$ age bracket and $24 \%$ of women in the 30-34 age bracket are illiterate, against $6 \%$ and $8 \%$ respectively of the men.

Thus, although the situation is relatively better in Tunisia than in other Arab countries, the performance in terms of gender equality is below international standards that Tunisia with a score of 49 out of 100 index of gender equality and that, because of the low participation of women in economic activity and also to issues of empowerment.

However, there is a strong mismatch between skills supply and labor demand. The past, all graduates were employed by the public sector, which still absorbs half of the graduates especially in social sciences, natural sciences, medicine and pharmacy. As against the private sector employs about one third of graduates in economics, management and law and senior technicians, specialties with the most unemployed, ie $46 \%$ of graduates in economics, management and law, and about $40 \%$ of senior technicians. In addition, the private sector employs more than half of young people without qualifications and high school, and about $60 \%$ of engineers.

To summarize the difference between the Tunisian economic structure remained at the stage of intensive production unskilled labor on the one hand, and the mass production of highly qualified labor supply on the other, giving an explanation largely to the low elasticity of employment growth (estimated at .43 to .47). You must note that although Tunisia suffers from higher unemployment of graduates, the inadequately educated workforce is among the obstacles business. This explains the one hand the high elasticity of substitution between jobs graduates and non-graduates in industrials ectors,especially inmechanics,electronics,food

and textiles. Thus, $62 \%$ of Tunisian companies complain of difficulties in recruiting skilled workers (2010), especially for Small and Medium Enterprises as well as companies that export. This creates an inadequate labor supply, especially in the textile (32\%) and health (34\%). Adds that the more educated a new employee is high, the longer it takes to become operational, so the quality of education is seen as a contributing factor to the inadequate supply of skills in the labor market. So the Tunisian educational system is considered relatively low compared with other countries, so that the policy of free access to education for all has been promoted at the expense of the quality of education.

\section{The Proposed Policies to Reduce Poverty and Inequality}

\subsection{Policies in the Short And Medium Term: Rethinking the Role of the State}

The orientation of public resources to the inner regions of Tunisia, which promotes job creation. Of that increased 
investment and public services, especially basic for the most marginalized inner regions will help minimize the spread of social welfare. Also transferred additional local communities in the poorest regions (who are better informed about the needs of the population and it more accountable) resources could improve the delivery of basic public services such as health and food.

\subsection{The Structural and Long-Termpolicy}

Despite the sustained growth and macroeconomic stability have succeeded in reducing absolute poverty, but these factors are not sufficient to reduce relative poverty. Tunisia is known to control the distribution pattern of growth and stimulate pro-poor growth to ensure development.

According to the African Developement Bank Group Public policies on investment and social services should mitigate the impact of regional disparities caused by the concentration of economic activities in coastal areas and create opportunities for development in poor inland regions of Tunisia.

These policies should be implemented in the former regime, namely the investment incentive measures in underserved inner regions remain relevant, but should focus primarily on the private sector. In this sense, they should follow a clear strategic approach, with a policy of infrastructure development and creation of the network of private companies able to grow, develop and facilitate business relations between the regions.

\subsection{The Implementation of a Results-Based Management, Transparent and Decentralized in Administration}

Decentralization of administration and fiscal decentralization stimulate local to be more independent and eventually improving the efficiency of service delivery public.

In addition, the establishment of a transparent system of governance based on the results, clearly intended to benefit the poor and underserved areas and marginalized.

\subsection{Improving the Efficiency of the Labormarket}

Tunisia has implemented several policies to support employment estimated at $0.7 \%$ of GDP, but have never been evaluated or modified object. According the African Development Bank Group an objective evaluation and rationalization of the existing mechanisms in order to improve employment policy, as to increase their efficiency. In addition, procedures and compensation of transparent and objective system for dismissals for economic and technical reasons should be put in place, an issue that disadvantage the competitiveness of enterprises is mainly eligibility for unemployment benefits. In this sense, the clarification of the status of private recruitment agencies by broadening their mission as an agency intermediary and increasing their numbers could help to improve the efficiency of the labor market and reducing of job insecurity for workers in these agencies.

\section{Conclusion}

In Tunisia, the uprising has started with a spontaneous social protest specially against unemployment and social discrimination in the most interiors regions, and in less than a month and against all expectations, the pressure of the street swept a regime up for 23 years According to our analysis, some issues raised require imediatly short-term solutions, while others issues require a structural change. A lot of governance problems must be resolved very quickly, in aim to give people a sign of change, restoration of public confidence, and give the chance to the new government to promote another culture, particularly in administration and in business. Regarding social issues, it is essential and urgent to address the social resentment, providing social services with greater admissibility and better targeting, and expanding the role of local communities.

In the long term, inclusive growth strategy could be adopted, providing for investment especially in infrastructure and public services intended to offset the different effects of economic concentration incertain areas, combined with a decentralization policy. To cope with rising unemployment, we need to create productive wealth but not in government investment in infrastructure (growth) while creating jobs through public investment will be needed in the short-term employment which will allow not only a good income but ensuring security, purchasing power and health. In fact, increasing the efficiency, both of labor market and education system will reduce unemployment, especially among young people.

However, youth unemployment is mainly due to the mismatch between labor supply and economic structure, which can't to be determined without addressing the problem of structural progression of the value chain and break the cycle of economy dual by a good integration of onshore sector in the global economy. Both revolution and democratization process in Tunisia offer a good opportunity to get rid of bottlenecks that have hindered its development. Today more than ever, civil society, which was at the origin of this policy change, will be responsible to participateinprogramdevelopment.Theprivatesector, whichhasoftensufferedfrom problems of governance in the public sector, will also play a fandamental role in improving the competitiveness and economic growth. While 
local channels used centralized power under the old regime, they will now serve local populations and influence public policy in their favor.

Ten years after the start of the revolution, Tunisians are still suffering from the poor economic health of their country. And the change in administrations is still pending. The country kept the same economic model, with the same problems as before the revolution of 2011 which ousted President Ben Ali from power with cries of "work, freedom, national dignity", The situation therefore continues to get worse.

\section{References}

Achy, L. (2011). Tunisia's economic challenges. The Carnegie Papers, Carnegie Middle East Center.

African Development Bank. (2021). Retrieved from https://www.afdb.org

Amara, M., \& Jemmali, H. (2017). On the decomposition of economic inequality: A methodology and an application to Tunisia. Working Paper $n^{\circ}$ 1096. Retrieved from https://erf.org.eg/app/uploads/2017/05/1096.pdf

Ayari, C. (2012). Perspectives du développement régional dans la Tunisie Post révolution. Centre de Réflexion stratégique pour le développement du Nord-Ouest.

Bayouth, M. (2012). Investissement en Infrastructure publique et croissance Publique et Croissance en Tunisie: Une analyse en équilibre générale calculable. Thèse de doctorat de l'université de Laval. Retrieved from https://corpus.ulaval.ca/jspui/bitstream/20.500.11794/23021/1/28823.pdf

Boubakri, A. (2015). Interpreting the Tunisian revolution: Beyond Bou'azizi in Routledge Handbook of the Arab Spring. Edited by Larbi Sadiki, Routledge, New York.

Ji-Hye, K., Sarah, S. O., Suk, W. B., Eun-Cheol, P., \& Sung-In, J. (2019). Int J Environ Res Public Health, 16(15), 2672. https://doi.org/10.3390/ijerph16152672

Magouri, A., Alaya, N., Ben, J. R., \& Mabkhout, A. (2018). Déséquilibres régionaux et inégalités sociales en Tunisie. Axes et actions prioritaires. Friedrich Ebert Stiftung. Tunis. Retrieved from http://library.fes.de/pdf-files/bueros/tunesien/14418.pdf.

Mahmoud, S. N. (2021). Making the Tunisian Resurgence. 107225 Éditeur University Library of Munich, Germany.

Michael, L., \& Martin, R. (1995). Chapter 41 Poverty and policy. Handbook of Development Economics, 3(Part B), 2551-2657. https://doi.org/10.1016/S1573-4471(95)30018-X

Premier Forum Annuel juillet. (2011).

Reliefweb. (2018). Tunisia: Overview Situation Report. Retrieved from https://reliefweb.int/report/tunisia/tunisia-overview-situation-report-30-june-2018

The universirty of chicago press journals. Retrieved from https://www.journals.uchicago.edu/

World Bank. (2014a). The unfinished revolution: Bringing opportunity. Good jobs and greater wealth to all Tunisians. Development Policy Review, May 2014, Report No. 86179-TN. Retrieved from https://www.worldbank.org/en/country/tunisia/publication/unfinished-revolution

World Bank. (2014b). Tunisia: Breaking the barriers to youth inclusion. World Bank, Report No. 89233-TN. Retrieved

from https://www.worldbank.org/en/country/tunisia/publication/tunisia-breaking-thebarriers-to-youth-inclusion

World Bank. (2014c). The opportunities of digitizing payments. A report by L. Klapper, \& D. Singer, World Bank Development Research Group of the World Bank, 28 August 2014. Retrieved from https://documents1.worldbank.org/curated/en/188451468336589650/pdf/903050WPREPLACEMENT0Box 385358B00PUBLIC0.pdf

World Bank. (2016). Poverty has fallen in the Maghreb, but inequality persists, Feature Story, 17 October 2016. Retrieved from https://www.worldbank.org/en/news/feature/2016/10/17/poverty-has-fallen-in-the-maghreb-but-inequality-p ersists

World Bank. (2021). Tunisia's Economic Update. Retrieved from https://www.worldbank.org/en/country/tunisia/publication/economic-updateapril2021

Yaghi, M. (2018). Frame Resonance, Tactical Innovation, and Poor People in the Tunisian Uprising. Research in 
Social Movements, $\quad$ Conflicts $\quad$ and $\quad$ Change, $\quad 42, \quad 115-143)$. https://doi.org/10.1108/S0163-786X20180000042005

\section{Copyrights}

Copyright for this article is retained by the author(s), with first publication rights granted to the journal.

This is an open-access article distributed under the terms and conditions of the Creative Commons Attribution license (http://creativecommons.org/licenses/by/4.0/). 